\title{
Usefulness of endoscopic ultrasound-guided fine needle aspiration for lymphadenopathy
}

\author{
YUKI TANISAKA, SHOMEI RYOZAWA, MASANORI KOBAYASHI, MAIKO HARADA, TSUTOMU KOBATAKE, \\ KUMIKO OMIYA, HIROTOSHI IWANO, SHIN ARAI, KOUICHI NONAKA and YUMI MASHIMO
}

Department of Gastroenterology, Saitama Medical University International Medical Center, Hidaka, Saitama 350-1298, Japan

Received May 15, 2017; Accepted November 16, 2017

DOI: 10.3892/ol.2018.7939

\begin{abstract}
Lymphadenopathy may be difficult to diagnose using imaging results alone. Endoscopic ultrasound-guided fine needle aspiration (EUS-FNA) may help to diagnose and determine the appropriate management of lymphadenopathy. EUS-FNA has been used as a safe and less invasive method for obtaining pathologic specimens from extraluminal lesions using endoscopic ultrasound. The present study evaluated the usefulness of EUS-FNA for lymphadenopathy. Between July 2013 and December 2016, 72 patients undergoing EUS-FNA for lymphadenopathy that could not be diagnosed solely using imaging were included. The present study evaluated the sensitivity, specificity, positive and negative predictive value, overall accuracy, helpfulness in determining the management of lymphadenopathy and EUS-FNA-associated complications. Of the 72 included patients, 8 were diagnosed with benign (inflammatory or reactive) lymphadenopathy. The diagnostic sensitivity, specificity, positive and negative predictive value, and overall accuracy were 95.3, 100, 100, 72.7 and $95.8 \%$, respectively. While EUS-FNA of metastatic nodes identified the origin in the majority of cases, the procedure resulted in a different histopathological diagnosis from the previous image-based diagnosis in 9 patients. Consequently, 2 patients with testicular cancer were administered bleomycin, etoposide, and cisplatin. An individual with GIST was administered imatinib, and a patient with prostate cancer was administered degarelix (antihormon drug). A total of 5 other patients received palliative medicine due to the change in diagnosis. EUS-FNA also helped determine the appropriate cancer management plan in other patients; specifically, based on the cytology of the metastatic lymph node, EUS-FNA helped determine the cancer stage, and to identify recurrence or the primary cancer from which tissue could not be
\end{abstract}

Correspondence to: Professor Shomei Ryozawa, Department of Gastroenterology, Saitama Medical University International Medical Center, 1397-1 Yamane, Hidaka, Saitama 350-1298, Japan

E-mail: ryozawa@saitama-med.ac.jp

Key words: endoscopic ultrasound-guided fine needle aspiration, lymphadenopathy, metastasis, cancer, origin collected. No EUS-FNA-associated symptoms were reported. To conclude, the present study suggested that EUS-FNA of suspected metastatic lymph nodes appears safe and useful for cancer staging and diagnosing recurrence. It may also useful for diagnosing patients whose collection of samples from the original cancer appeared impractical. EUS-FNA for lymphadenopathy that may not be diagnosed with imaging alone may assist in diagnosis and help to determine the appropriate management strategy.

\section{Introduction}

Benign and malignant lymphadenopathy appear similar in imaging studies, and therefore may be difficult to diagnose. Diagnostic imaging studies, including those using ultrasound, computed tomography and magnetic resonance imaging, are required to whole-body assess patients for potentially malignant lymphadenopathy. Imaging modalities including ultrasound, computed tomographic scan and positron emission tomography have become more advanced in the previous 10 years $(1,2)$. However, while diagnostic imaging may help to identify metastases in numerous patients with cancer, in the presence of inflammation or multiple tumors, differentially diagnosing patients may be challenging for multiple reasons, including the presence of metastatic lymph nodes of unknown origin (3-5). In addition, deciding if lymphadenopathy that appears benign should be followed conservatively without treatment using the diagnostic imaging results alone may be challenging.

Histopathologically diagnosing a suspected metastatic lymph node may substitute for diagnosing the primary cancer when tissue samples from this primary cancer may not be collected for histopathological analysis. Open thoracic surgery, laparotomy, or other procedures including mediastinoscopy or laparoscopy were required; however, these procedures were carried out under general anesthesia, and therefore required a lot of time and expense. These procedures are also associated with causing tissue damage, which may cause delay to the start of therapy. Patients exhibiting more serious medical conditions (including hypotension and low performance status) are also exposed to greater anesthetic and surgical associated risks. If imaging and puncturing may be performed under endoscopic ultrasound (EUS) guidance, the enlarged lymph node tissue may be collected for diagnosis by EUS-guided fine needle aspiration (FNA). EUS-FNA material was used for cytology 
and histological review. This collected tissue may be used to determine malignancy and identify the origin of the metastasis $(3,6,7)$. The present study retrospectively evaluated the usefulness of EUS-FNA for patients with lymphadenopathy treated at Saitama Medical University International Medical Center (Saitama, Japan).

\section{Materials and methods}

Patients. The present study included 72 patients (42 males; 30 females; mean age, 67 years; age range, 24-85 years) who underwent EUS-FNA between July 2013 and December 2016 for lymphadenopathy that could not be diagnosed based solely on imaging, at the Department of Gastroenterology, Saitama Medical University International Medical Center. The inclusion criteria were as follows: Lymphadenopathy $>10 \mathrm{~mm}$ in maximal diameter; lymphadenopathy indicated by computed tomography to be approachable by EUS-FNA from the esophagus, stomach, duodenum or lower gastrointestinal tract; and suspected metastatic lymph nodes with a primary cancer for which tissue could not be collected. The exclusion criteria were as follows: Lymphadenopathy permitting a superficial approach to collect tissue, e.g., superficial lymphadenopathy; treatment with anti-thrombotic agents that may not be discontinued; and the presence of unavoidable blood vessels in the puncture route.

The present study complied with the Declaration of Helsinki, as revised in Brazil 2013. All patients provided written informed consent for EUS-FNA. The Institutional Review Board of Saitama Medical University International Medical Center approved the present study.

Methods. A linear echoendoscope (GF-UCT260; Olympus Optical Co., Ltd., Tokyo, Japan) was used for EUS-FNA. A 22- or 25-gauge needle (Expect ${ }^{\mathrm{TM}}$ Slimline; Boston Scientific Corporation, Marlborough, MA, USA) was used for the EUS-guided procedure. Following lymph node aspiration and stylet removal, negative pressure was provided using a $20 \mathrm{ml}$ syringe. After 20 rapid suction strokes, the negative pressure was released and the needle was removed. The aspiration sample was pushed out onto a slide glass by re-inserting the stylet or by creating positive pressure using air. The sample was examined macroscopically to identify whether it was white, as white indicates histologic core specimen (8), not the vascular content. If macroscopic results demonstrated an increase in blood components, the negative pressure level used for the subsequent needle aspiration procedures was decreased as necessary. The material, which included both the tissue and blood components, was stored in $10 \%$ formalin (room temperature) for histopathological diagnosis and cytology. Since Saitama Medical University International Medical Center does not perform on-site cytology, the EUS-FNA procedure was repeated until the sample volume was macroscopically considered adequate for histopathological diagnosis, including for immunostaining, as long as the procedure could be continued. It is important to note that due to the use of automated immunohistochemical staining, the present study could not clarify the number of repeats required. The present study performed EUS-FNA and samples were analyzed by pathologists from the Department of Pathology, Saitama Medical University International Medical Center (Saitama, Japan). If complications including major bleeding occurred during the procedure, the procedure would be stopped immediately. All patients were hospitalized for the procedure and received follow-up until the following day. Patients were discharged if they exhibited no complications and were asked to return for an outpatient visit $\sim 1$ week later.

Cytological examination. Smears and needle rinses were alcohol-fixed (95\% ethanol, room temperature for $15 \mathrm{~min}$ ) and subsequently Papanicolau stained in the laboratory. All specimens were examined by a cytopathologist to render a final diagnosis according to a five tier diagnostic system: Non-diagnostic, negative for malignancy, atypical, suspicious for malignancy and positive for malignancy.

Pathological examination. Biopsy cores were fixed in $10 \%$ neutral buffered formalin (room temperature, $20 \mathrm{~h}$ ), embedded in paraffin and cut into $4 \mu \mathrm{m}$ thick serial sections for hematoxylin and eosin (H\&E) staining. Slides were evaluated using a BX51 microscope (magnification, $\mathrm{x} 2, \mathrm{x} 4, \mathrm{x} 10, \mathrm{x} 20, \mathrm{x} 40$ and x60; Olympus, Japan). The protocol for the H\&E staining in the pathological examination was as follows; deparaffinized sections twice with xylene to remove the paraffin for complete rehydration, 10 min each, rehydrate samples 3 times with 100, 95 and $80 \%$ ethanol, 5 min each, followed by incubation with 95\% ethanol for $2 \mathrm{~min}$ and $70 \%$ ethanol for $2 \mathrm{~min}$. Samples were then washed with distilled water and stained with Carrazzi's hematoxylin solution for $10 \mathrm{~min}$ and then rinsed under tap water for $10 \mathrm{~min}$. Samples were then counterstained with eosin-phloxine solution for $5 \mathrm{~min}$ and dehydrated 4 times with $80,95,100$ and $100 \%$ ethanol 5 min each for complete dehydration. Samples were treated twice with xylene for $5 \mathrm{~min}$ each for dealcoholization, and then mounted with xylene based mounting medium. This protocol was performed at room temperature in all stages.

Immunohistochemical analysis. Immunohistochemical analysis was performed on the formalin-fixed, paraffin-embedded sections. The $4 \mu \mathrm{m}$ thick sections were mounted on poly-L-lysine-coated slides and deparaffinized and dehydrated through graded alcohol series and water. Antigen retrieval was performed, and sections were immunostained using the LSAB universal kit in the Benchmark system (Ventana Medical Systems Inc.; Roche Diagnostics, Basel, Switzerland). The antibodies that we used were listed in (Table I). The heating temperature was room temperature. Washing regent was EZ prep and no rehydration was performed. An automated immunohistochemistry protocol was used as follows: Deparaffinization, $75^{\circ} \mathrm{C}$; cell conditioning, $95-100^{\circ} \mathrm{C}$; primary antibody, $37^{\circ} \mathrm{C}$; incubation $16-32 \mathrm{~min}$. Endogenous peroxidase blocking was carried out with I-VIEW inhibitor for $4 \mathrm{~min}$. Endogenous biotin blocking was performed using blocker A for $4 \mathrm{~min}$ and blocker B for $4 \mathrm{~min}$. Samples were incubated with secondary antibody (I-VIEW BIOTIN Ig) for $8 \mathrm{~min}$. Samples were visualized using I-VIEW DAB and I-VIEW H2O2, incubated for $8 \mathrm{~min}$, and I-VIEW COPPER incubated for $4 \mathrm{~min}$. Slides were evaluated using a BX51 microscope ( $\mathrm{x} 2, \mathrm{x} 4$, $\mathrm{x} 10$, $\mathrm{x} 20, \mathrm{x} 40, \mathrm{x} 60$ )

Lesions were evaluated using several primary antibodies. The staining protocol of each antibody was performed 
Table I. Antibodies that were used for immunohistochemistry.

\begin{tabular}{|c|c|c|c|c|c|c|}
\hline Antibodies & $\begin{array}{l}\text { Source } \\
\mathrm{r} / \mathrm{m}\end{array}$ & Clone & Company & Dilution & $\begin{array}{l}\text { Heat-induced epitope } \\
\text { retrieval M/S/E }\end{array}$ & Vis method \\
\hline $\mathrm{CD} 3$ & $\mathrm{~m}$ & $2 \mathrm{GV} 6$ & Roche & $\mathrm{x} 1$ & $\mathrm{~S}$ & VENTANA \\
\hline CD5 & $\mathrm{m}$ & $4 \mathrm{C} 7$ & Leica & $\mathrm{x} 25$ & $S$ & $\begin{array}{l}\text { iVIEW } \\
\text { DAB Detection kit } \\
\text { VENTANA } \\
\text { Automated immune- } \\
\text { histochemistry }\end{array}$ \\
\hline CD10 & $\mathrm{m}$ & $56 \mathrm{C} 6$ & & $\mathrm{x} 40$ & S & \\
\hline CD20cy & $\mathrm{m}$ & L26 & DAKO & $\mathrm{x} 400$ & S & \\
\hline MUM-1 & $\mathrm{m}$ & MUM1p & & $\mathrm{x} 50$ & M & \\
\hline Bcl-1 (CyclinD1) & $\mathrm{m}$ & DSC-6 & & $x 50$ & M & \\
\hline $\mathrm{Bcl}-2$ & $\mathrm{~m}$ & 124 & & $\mathrm{x} 100$ & $\mathrm{~S}$ & \\
\hline Bcl-6 & $\mathrm{m}$ & PG-B6 & & $\mathrm{x} 20$ & S & \\
\hline CK7 & $\mathrm{m}$ & OV-TL 12/30 & & $\mathrm{x} 100$ & $\mathrm{E}$ & \\
\hline CK20 & $\mathrm{m}$ & Ks20.8 & & $\mathrm{x} 100$ & $\mathrm{M}$ & \\
\hline TTF-1 & $\mathrm{m}$ & 8G7G3/1 & & $x 50$ & M & \\
\hline $\begin{array}{l}\text { Pax8 } \\
\text { ER }\end{array}$ & $\mathrm{r}$ & Polyclonal & Proteintech & $\mathrm{x} 200$ & M & \\
\hline $\begin{array}{l}\text { Estrogen receptor } \\
\text { PSA }\end{array}$ & $\mathrm{m}$ & SP-1 & Roche & $\mathrm{x} 1$ & $S$ & \\
\hline $\begin{array}{l}\text { Prostate-specific } \\
\text { Antigen }\end{array}$ & $\mathrm{m}$ & ER-PR8 & DAKO & $\mathrm{x} 100$ & M & \\
\hline S-100 & $\mathrm{r}$ & Polyclonal & & $x 500$ & M & \\
\hline p40 & $\mathrm{r}$ & Polyclonal & Calbiochem & $x 500$ & $S$ & \\
\hline $\mathrm{CDX}-2$ & $\mathrm{~m}$ & CDX2-88 & BioGenex & $\mathrm{x} 50$ & S & \\
\hline DOG-1 & $\mathrm{m}$ & K9 & Leica & $\mathrm{x} 100$ & $S$ & \\
\hline Chromogranin A & $\mathrm{r}$ & Polyclonal & DAKO & $\mathrm{x} 100$ & M & \\
\hline $\begin{array}{l}\text { Synaptophysin } \\
\text { CD117, }\end{array}$ & $\mathrm{m}$ & $27 \mathrm{G} 12$ & Nichirei & $\mathrm{x} 1$ & M & \\
\hline c-kit Oncoprotein & $\mathrm{r}$ & Polyclonal & DAKO & $x 20$ & M & \\
\hline Desmin & $\mathrm{m}$ & D33 & & $\mathrm{x} 1$ & S & \\
\hline
\end{tabular}

Heat-induced epitope retrieval M/S/E; CC1/Cell Conditioning Solution (Roche), 95-100 ${ }^{\circ} \mathrm{C} . \mathrm{M}$, mild 30 min conditioning; S, standard 60 min Conditioning; E, extended 90 min conditioning. Automated immune-histochemistry; BenchMark XT IHC/ISH Staining Module. Ab, antibody; $\mathrm{r} / \mathrm{m}$, rabbit/mouse.

according to each data sheet. For detection of lesions, the sections were incubated with 3,3'-diaminobenzidine for $8 \mathrm{~min}$ at room temperature. With each set of staining processes, known positive and negative control samples were included. Positive control tissues were as follows: CD3, CD5, CD10, CD20cy, MUM-1, Bcl-1 (Cyclin D1), Bcl-2, and Bcl-6 were tonsil; CK7, CK20, and CDX-2 were tissues of Cytokeratin (esophagus, colon and urinary bladder); ER (Estrogen Receptor) was mammary gland; P40 was tissues of Squamous cell carcinoma; DOG-1 and CD117 c-kit Oncoprotein were tissues of Gastrointestinal stromal tumor; TTF-1, Pax8, PSA, S-100, Chromogranin A, Synaptophysin, and Desmin were multi-control tissues (Cerebrum, thyroid, lung, liver, pancreas, kidney, prostate). Cells within the positive control tissues that are known to be negative for each protein were used as negative controls in the present study. All specimens were diagnosed by a pathologist in Department of Pathology, Saitama Medical University International Medical Center (Saitama, Japan).

The present study evaluated the sensitivity, specificity, positive and negative predictive value, overall accuracy, helpfulness for determining the management of lymphadenopathy, and the EUS-FNA-associated complications. The type of cancer was predicted prior to surgery by blood examination, computed tomography or magnetic resonance imaging.

The final diagnosis used the EUS-FNA-based tissue diagnosis or postoperative tissue diagnosis and the clinical course in patients who underwent surgery. Lymphadenopathy was used to diagnose EUS-FNA-based tissue as benign, with whole-body assessments were performed, including imaging modalities after 6 months. If the image results and clinical course were without aggravation, they were diagnosed as 
Table II. Clinicodemographic characteristics of the study population $(n=72)$.

\begin{tabular}{|c|c|}
\hline Characteristics & Number of patients \\
\hline Male/female & $42 / 30$ \\
\hline Mean age (range) & 67 years $(24-85)$ \\
\hline \multicolumn{2}{|l|}{ History of different cancer } \\
\hline Gastric cancer & 5 \\
\hline Colon cancer & 4 \\
\hline Pancreatic cancer & 4 \\
\hline Bile duct cancer & 3 \\
\hline Hepatocellular carcinoma & 2 \\
\hline Lung cancer & 2 \\
\hline Esophageal cancer & 1 \\
\hline Cervical cancer & 1 \\
\hline Renal pelvis cancer & 1 \\
\hline Malignant lymphoma & 1 \\
\hline $\begin{array}{l}\text { Median longest diameter of } \\
\text { the lymph node, } \mathrm{mm} \text { (range) }\end{array}$ & $21(10-90)$ \\
\hline \multicolumn{2}{|l|}{ Puncture site, n (\%) } \\
\hline Esophagus & $5(6.9)$ \\
\hline Stomach & $58(80.6)$ \\
\hline Duodenum & $8(11.1)$ \\
\hline Rectum & $1(1.4)$ \\
\hline \multicolumn{2}{|l|}{ Aspiration needle size, n (\%) } \\
\hline 22-gauge & $67(93.1)$ \\
\hline 25-gauge & $5(6.9)$ \\
\hline $\begin{array}{l}\text { Mean number of puncture } \\
\text { attempts (range) }\end{array}$ & $3.8(1-8)$ \\
\hline Malignant/benign, $\mathrm{n}$ & $64 / 8$ \\
\hline
\end{tabular}

benign. If insufficient EUS-FNA sample volume was gained surgical biopsy was performed.

Of the 72 patients enrolled in the present study, 24 (33.3\%) had a history of a different type of cancer (Table II). The median longest diameter of the examined lymph node was $21 \mathrm{~mm}$ (10-90 mm). Transesophageal, transgastric, transduodenal and transcolorectal FNA were performed in 5, 58, 8 and 1 patient, respectively. A 22-gauge needle was used in 67 patients, while a 25-gauge needle was used in 5 patients. The mean number of puncture attempts was 3.8 (range, 1-8).

\section{Results}

The final diagnosis was malignancy in 64 patients and benign lymphadenopathy in 8 patients (Table II). The 64 malignancies included malignant lymphoma in 33 patients (B-cell lymphoma in 30 patients, T-cell lymphoma in 3 patients), bile duct cancer in 6 patients, malignancy of unknown origin in 5 patients, pancreatic cancer in 4 patients, gastric cancer in 3 patients, lung cancer in 3 patients, testicular cancer in 2 patients, ovarian cancer in 2 patients, prostate cancer in 1 patient, esophageal cancer in 1 patient, colon cancer in 1 patient, cancer of the duodenal papilla in 1 patient, adrenal paraganglioma in 1 patient and a gastrointestinal stromal
Table III. Final diagnoses of the lymphadenopathies $(n=72)$.

Type of cancer

Number of patients

\begin{tabular}{lr}
\hline Malignant & 64 \\
Benign & 8 \\
Malignant lymphoma & 33 \\
Reactive lymphadenopathy & 8 \\
Bile duct cancer & 6 \\
Origin unknown & 5 \\
Pancreatic cancer & 4 \\
Gastric cancer & 3 \\
Lung cancer & 3 \\
Testicular cancer & 2 \\
Ovarian cancer & 2 \\
Prostate cancer & 1 \\
Esophageal cancer & 1 \\
Colon cancer & 1 \\
Cancer of the duodenal papilla & 1 \\
Adrenal paraganglioma & 1 \\
Gastrointestinal stromal tumor & 1 \\
\hline
\end{tabular}

tumor in 1 patient (Table III). Of the 33 patients with a final diagnosis of lymphoma, the disease was subtyped according to the classification of lymphoid neoplasms (World Health Organization; 2016) (9) via EUS-FNA in 23 patients (69.7\%).

The origin was identified using EUS-FNA in $87.5 \%$ (56/64) of metastatic lymph nodes. The histopathological diagnosis differed from that which had been expected based on the pre-procedural images in 9 patients and the cancer management for these patients was subsequently changed (Table IV), for example, alternate anticancer drugs were administered. The present study pre-procedurally predicted that hepatocellular carcinoma would be diagnosed in a 77-year-old male patient, as the patient had undergone surgery for hepatocellular carcinoma 4 years previously, and the lymphadenopathy was due to recurrence (Table IV). In 8 cases, for which the present study pre-procedurally predicted lymphoma, there was no history of cancer or multiple lymphadenopathies. Furthermore, certain patients exhibited an elevated soluble interleukin-2 receptor level. In a 57-year-old male patient (Table IV), the presence of multiple lymphadenopathies suggestive of malignant lymphoma was identified to be metastatic prostate cancer based on the histopathology examination following EUS-FNA, and therefore the cancer management for this patient was subsequently changed. This patient was administered degarelix (antihormon drug; Fig. 1).

Of the 64 patients with a final diagnosis of malignancy, the diagnosis was based on EUS-FNA alone in 61 patients. Of the remaining 3 patients whose malignancy could not be diagnosed using EUS-FNA alone, the EUS-FNA sample volume was insufficient in 1 patient with current lung and esophageal cancer. This particular patient received fluorouracil (FP; $1200 \mathrm{mg}$ dose between days 1 to 5) and cisplatin (120 mg dose on day 1) treatment every 4 weeks. This patient received 6 courses of FP therapy for lung cancer as this was more advanced compared with the esophageal cancer. The 
Table IV. Diagnostic changes following endoscopic ultrasound-guided fine needle aspiration in 9 patients.

\begin{tabular}{|c|c|c|c|c|c|c|}
\hline Sex & $\begin{array}{l}\text { Age, } \\
\text { years }\end{array}$ & $\begin{array}{l}\text { Punctured } \\
\text { lymph node }\end{array}$ & $\begin{array}{l}\text { Diameter } \\
(\mathrm{mm})\end{array}$ & $\begin{array}{c}\text { Cytology } \\
\text { histopathology }\end{array}$ & $\begin{array}{c}\text { Pre-procedural } \\
\text { prediction }\end{array}$ & $\begin{array}{c}\text { Final } \\
\text { diagnosis }\end{array}$ \\
\hline Female & 50 & Para-aortic & 42 & Atypical paraganglioma & Lymphoma & Paraganglioma \\
\hline \multirow[t]{2}{*}{ Male } & 77 & Para-aortic & 12 & Positive & & \\
\hline & & & & Adenocarcinoma & $\mathrm{HCC}$ & Metastasis of unknown origin \\
\hline \multirow[t]{2}{*}{ Female } & 80 & Para-aortic & 30 & Positive & & \\
\hline & & & & Adenocarcinoma & Lymphoma & Metastasis of ovarian cancer \\
\hline \multirow[t]{2}{*}{ Male } & 24 & Proximate to the & 50 & Positive & & \\
\hline & & abdominal aorta & & Germ cell tumor & Lymphoma & Metastasis of testicular cancer \\
\hline \multirow[t]{2}{*}{ Male } & 57 & Para-aortic & 21 & Positive & & \\
\hline & & & & Adenocarcinoma & Lymphoma & Metastasis of prostate cancer \\
\hline \multirow[t]{2}{*}{ Male } & 74 & Proximate to the & 35 & Positive & & \\
\hline & & celiac artery & & Adenocarcinoma & Lymphoma & Metastasis of bile duct cancer \\
\hline \multirow[t]{2}{*}{ Male } & 40 & Para-aortic & 15 & Positive & & \\
\hline & & & & Germ cell tumor & Lymphoma & Metastasis of testicular cancer \\
\hline \multirow[t]{2}{*}{ Male } & 73 & Para-aortic & 26 & Positive & & \\
\hline & & & & GIST & Lymphoma & Metastasis of GIST \\
\hline \multirow[t]{2}{*}{ Female } & 75 & Para-aortic & 26 & Atypical & & \\
\hline & & & & Serous carcinoma & Lymphoma & Metastasis of duodenal papilla \\
\hline
\end{tabular}
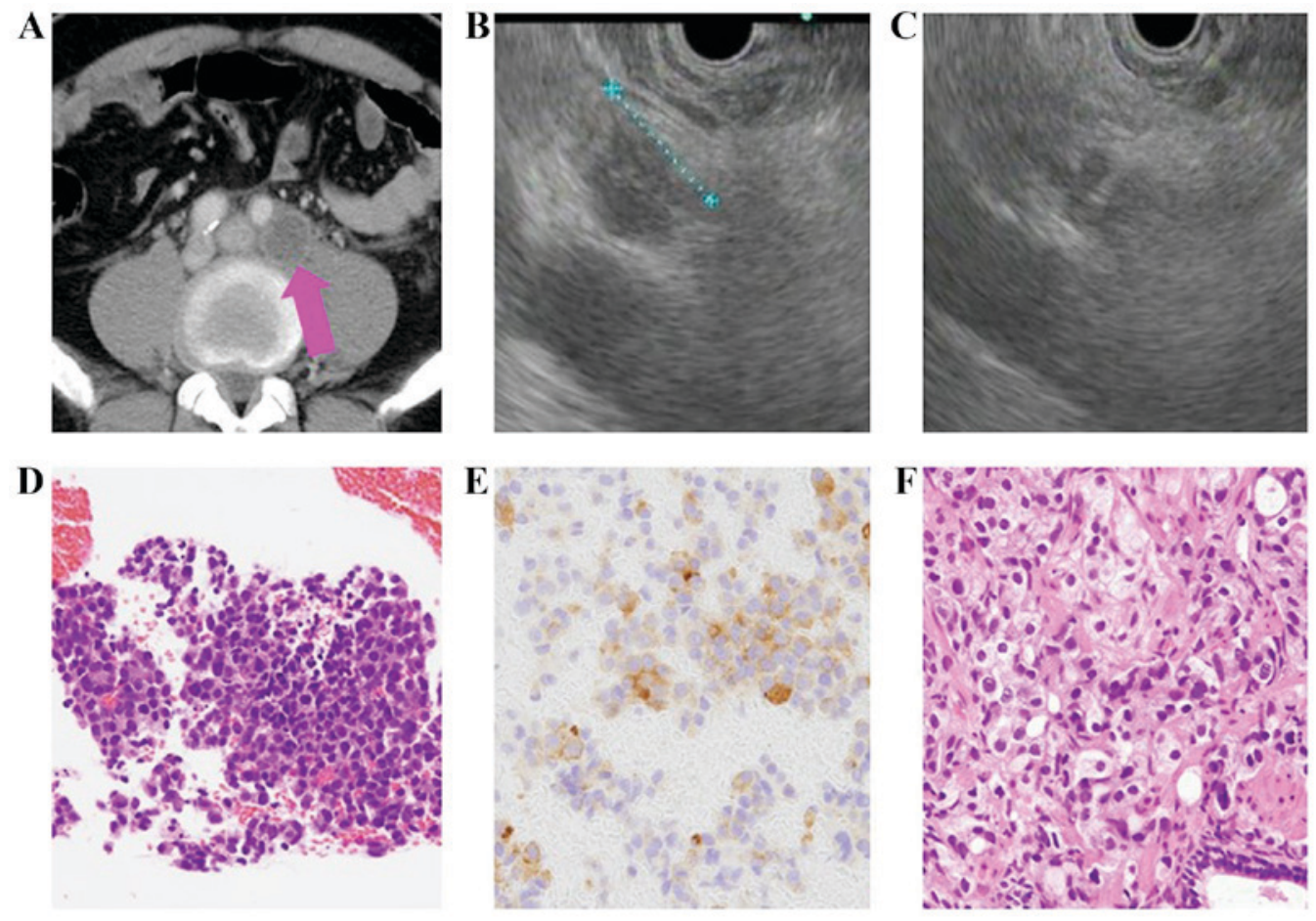

Figure 1. A case which changed diagnosis from lymphoma to prostate cancer following EUS-FNA (57 years old male). (A) Swollen para aortic lymph nodes. Pink arrow indicates the swollen lymph node in the computed tomographic scan. (B) 10 mm lymph node using EUS. (C) EUS-FNA was performed using 22-gauge needle. The lymph node was punctured using the needle. (D) Adenocarcinoma. (E) PSA staining was positive. It indicated the presence of prostate cancer. (F) Prostate carcinoma diagnosis via needle biopsy.

remaining 2 patients, who were suspected to exhibit malignant lymphoma, underwent laparotomy biopsy due to insufficient EUS-FNA sample volume. These patients were diagnosed with lymphoma and received rituximab $\left(375 \mathrm{mg} / \mathrm{m}^{2}\right.$ of body surface area on day 1), cyclophosphamide $\left(750 \mathrm{mg} / \mathrm{m}^{2}\right.$ of body surface area on day 1), doxorubicin hydrochloride $\left(50 \mathrm{mg} / \mathrm{m}^{2}\right.$ of body surface area on day 1$)$, vincristine sulfate $\left(1.4 \mathrm{mg} / \mathrm{m}^{2}\right.$ of body surface area on day 1), and prednisolone (100 $\mathrm{mg}$ dose between 
Table V. Patients for whom endoscopic ultrasound-guided fine needle aspiration helped diagnose recurrence.

\begin{tabular}{|c|c|c|c|c|c|c|}
\hline Sex & $\begin{array}{l}\text { Age, } \\
\text { years }\end{array}$ & Origin & $\begin{array}{l}\text { Punctured } \\
\text { lymph node }\end{array}$ & $\begin{array}{l}\text { Diameter } \\
\quad(\mathrm{mm})\end{array}$ & $\begin{array}{c}\text { Cytology } \\
\text { histopathology }\end{array}$ & $\begin{array}{c}\text { Duration of } \\
\text { recurrence (months) }\end{array}$ \\
\hline Male & 73 & Lung & Mediastinal & 22 & $\begin{array}{l}\text { Positive } \\
\text { Squamous cell } \\
\text { carcinoma }\end{array}$ & 20 \\
\hline Male & 77 & Stomach & Lesser curvature & 11 & $\begin{array}{l}\text { Positive } \\
\text { Adenocarcinoma }\end{array}$ & 42 \\
\hline Male & 74 & Stomach & $\begin{array}{l}\text { Proximate to the common } \\
\text { hepatic artery }\end{array}$ & 15 & $\begin{array}{l}\text { Positive } \\
\text { Adenocarcinoma }\end{array}$ & 8 \\
\hline Female & 83 & Bile duct & $\begin{array}{l}\text { Proximate to the } \\
\text { superior mesenteric artery }\end{array}$ & 20 & $\begin{array}{l}\text { Positive } \\
\text { Adenocarcinoma }\end{array}$ & 38 \\
\hline Female & 68 & Pancreas & $\begin{array}{l}\text { Proximate to the } \\
\text { common hepatic artery }\end{array}$ & 20 & $\begin{array}{l}\text { Positive } \\
\text { Atypical cell }\end{array}$ & 11 \\
\hline Male & 75 & Colon & Mediastinal & 22 & $\begin{array}{l}\text { Positive } \\
\text { Adenocarcinoma }\end{array}$ & 27 \\
\hline Male & 73 & Lung & Mediastinal & 12 & $\begin{array}{l}\text { Positive } \\
\text { Squamous cell } \\
\text { carcinoma }\end{array}$ & 20 \\
\hline
\end{tabular}

Table VI. Endoscopic ultrasound-guided fine needle aspiration of metastatic lymph nodes in patients with no available sample of the original cancer tissue.

\begin{tabular}{|c|c|c|c|c|c|c|}
\hline Sex & $\begin{array}{l}\text { Age, } \\
\text { years }\end{array}$ & $\begin{array}{l}\text { Cancer } \\
\text { origin }\end{array}$ & $\begin{array}{c}\text { Reason for } \\
\text { unavailable tissue sample }\end{array}$ & $\begin{array}{l}\text { Punctured } \\
\text { lymph node }\end{array}$ & $\begin{array}{l}\text { Diameter } \\
(\mathrm{mm})\end{array}$ & $\begin{array}{l}\text { Cytology } \\
\text { histopathology }\end{array}$ \\
\hline Male & 70 & Stomach & $\begin{array}{l}\text { Unable to collect } \\
\text { via biopsy }\end{array}$ & $\begin{array}{l}\text { Proximate to the } \\
\text { common hepatic artery }\end{array}$ & 20 & $\begin{array}{l}\text { Negative } \\
\text { Adenocarcinoma }\end{array}$ \\
\hline Male & 63 & Esophagus & Unable to collect via biopsy & Gastric cardia & 39 & $\begin{array}{l}\text { Positive } \\
\text { Squamous cell } \\
\text { carcinoma }\end{array}$ \\
\hline Male & 74 & Stomach & Unable to collect via biopsy & $\begin{array}{l}\text { Proximate to the } \\
\text { common hepatic artery }\end{array}$ & 41 & $\begin{array}{l}\text { Positive } \\
\text { Adenocarcinoma }\end{array}$ \\
\hline Male & 77 & Pancreas & $\begin{array}{l}\text { Gastrointestinal stenosis } \\
\text { present }\end{array}$ & $\begin{array}{l}\text { Proximate to the } \\
\text { celiac artery }\end{array}$ & 10 & $\begin{array}{l}\text { Positive } \\
\text { Adenocarcinoma }\end{array}$ \\
\hline
\end{tabular}

days 1 to 5) treatment every 3 weeks. Both patients received 5 courses. All 8 patients with a benign diagnosis exhibited reactive lymphadenopathy, which was not aggravated during the 6-month follow-up. In 72 cases, 8 patients were diagnosed as benign and 64 as malignant. The EUS-FNA diagnosis of benign and malignancy was 11 patients and 61 patients. The sensitivity, specificity, positive predictive value, negative predictive value and accuracy of malignancy diagnosed by EUS-FNA were $95.3 \%$ (61/64), 100\% (8/8), 100\% (61/61), $72.7 \%$ (8/11) and $95.8 \%(69 / 72)$.

EUS-FNA helped to identify the origin of the cancer in the majority of the patients $(56 / 64 ; 87.5 \%)$. The procedure also assisted in determining the appropriate cancer management plan; specifically, EUS-FNA assisted with cancer staging, diagnosing recurrence (Table $\mathrm{V}$ ) and diagnosing using the metastatic lymph node when collecting samples from the original cancer was impractical (Table VI). In 1 patient (a 63-year-old male; Table VI) with suspected esophageal cancer, EUS-FNA was performed on an enlarged cardiac lymph node as no definitive diagnosis could be made following repeated biopsies and the collection of original cancer tissue was impossible. EUS-FNA subsequently revealed a diagnosis of squamous cell carcinoma (Fig. 2). No patient that underwent EUS-FNA reported any complications.

\section{Discussion}

The proposed EUS image-based diagnostic criteria for malignant lymphadenopathy include round or oval cross-sections, sharp demarcations, internal hypoechoic features and $>10 \mathrm{~mm}$ largest diameter (3). Overall, only EUS image-based diagnostic accuracy is $80 \%$ when all criteria are met (3). However, differentially diagnosing inflammation and metastasis, and determining the most appropriate cancer management using EUS of 

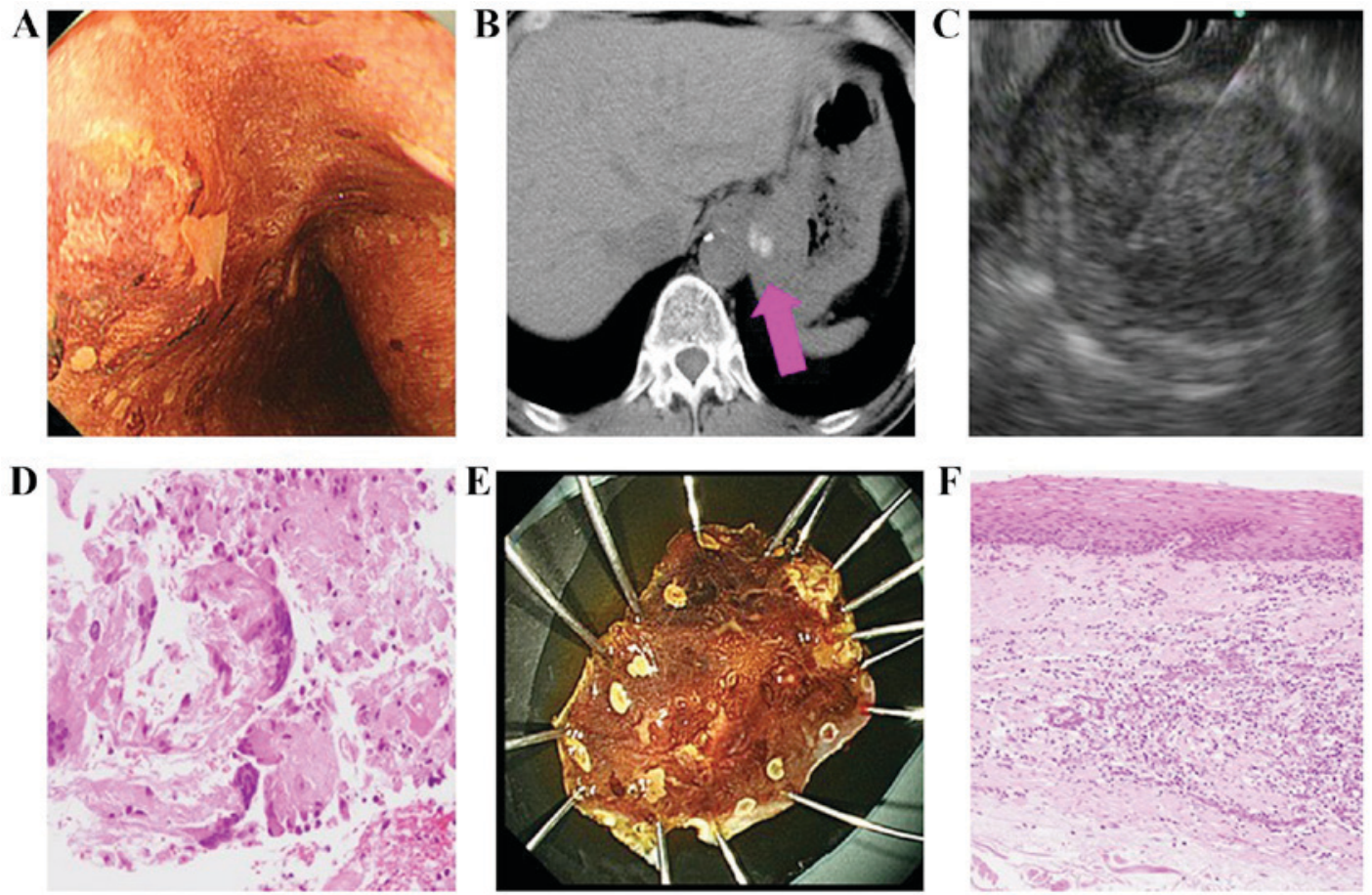

Figure 2. A case which biopsy of the primary lesion was challenging (63 years old male, suspected diagnosis was esophageal carcinoma). (A) Suspected esophagal carcinoma; however, biopsy of the primary lesion was negative. (B) Swollen cardiac lymph node. Pink arrow indicates the swollen lymph node in the computed tomographic scan. (C) Endoscopic ultrasound-guided fine needle aspiration was performed using 22-gauge needle. The lymph node was punctured using the needle. (D) Squamous cell carcinoma. (E) ESD was performed for diagnosis. This was the specimen following ESD. (F) Esophageal carcinoma diagnosis. ESD, endoscopic submucosal dissection.

lymphadenopathy alone is challenging (3-5). Although contrast EUS has become increasingly diagnostically accurate, EUS results alone remain insufficient for diagnosing patients $(4,5)$.

EUS-FNA is useful when EUS alone is not reliable. Already a part of general practice, EUS-FNA for lymphadenopathy helps to identify metastasis and diagnose inflammatory diseases, including tuberculosis (5-7). Previous studies have reported that concurrent EUS and EUS-FNA increase the overall diagnostic accuracy $(3,6,7)$. Recently, multiple skills including 'funning technique' or 'slow-pull technique' were reported to achieve successful EUS-FNA results (10). Nakahara et al (11) reported a $96 \%$ overall diagnostic accuracy of EUS-FNA for abdominal lymphadenopathy of unknown origin in 57 patients. EUS-FNA is used for mediastinal lymphadenopathy, with a sensitivity of $82-93 \%$ and a specificity of $89-100 \%$ (12-14). In addition, EUS-FNA is used with a lower gastrointestinal tract approach for pelvic lymphadenopathy (15). This procedure has been reported to be useful for urological cancer types, including prostate and bladder cancer, with a sensitivity of $94.4 \%$ (15). EUS-FNA was also useful for diagnosing malignant lymphoma. Yasuda et al (16) subtyped lymphoma according to the World Health Organization classification in 44 of their 48 patients, who could subsequently receive multiple tailored treatments, including chemotherapy. They also used a 19-gauge needle to perform EUS-FNA, which was reportedly safely performed, and complications occurred in $1 \%$ of patients.

In accordance with these previous studies, the present study concluded that EUS-FNA is minimally invasive and accurate for diagnosing endoscopically approachable lymphadenopathy. In the present study, a 25 -gauge needle was used in 5 cases. In 3 cases, the lesions were punctured with a tight angular scope position. In 2 cases, small blood vessels were present within the lesions. In these cases, a thinner (25-gauge) needle was used. The present study performed EUS-FNA for lymphadenopathy in 72 patients, with an increased tissue collection rate and without any ensuing complications. The present study attributed the absence of complications to the use of a 25-gauge needle for lesions with a bleeding risk due to the small blood vessels located within the lesion. The outcomes of EUS-FNA were similar to those reported in previous studies, with a sensitivity, specificity, positive predictive value, negative predictive value and overall accuracy of 95.3 (61/64), 100 (8/8), 100 (61/61), 72.7 (8/11) and 95.8\% (69/72), respectively. The rate of subtyping malignant lymphoma according to the WHO classification (9) was $69.7 \%$ (23/33); this was low compared with the rate reported by Yasuda et al (16). To increase the rate of subtyping, subsequent studies should increase the sample volume, perhaps by using a 19-gauge needle, as reported in another previous study

A prior study suggested that although thinner (22- or 25-gauge) needles provide a decreased volume of cellular material compared with that which larger (19-gauge) needles provide, the specimens from the former are less contaminated by blood and are therefore easier to evaluate (17). In addition, thinner needles may be easier to use due to increased flexibility, particularly for locations that require the scope to bend (17). Therefore, the majority of studies on EUS-FNA have been performed using 22 -gauge needles $(11,12,15)$. As aforementioned, a 25-gauge needle is suitable for lesions that require puncturing in a tight angulated scope position and lesions that contain small blood vessels. For subtyping malignant lymphoma, a 19-gauge needle may be suitable. 
Immunostaining was revealed to be useful for diagnosing based on the sample collected using EUS-FNA in the present study. If the specimen was histologically similar in regards to EUS-FNA and surgical results, recurrent cancer would be diagnosed.

Providing accurate clinical information to the pathologist ensures appropriate differential diagnosis. Sharing information with the pathologist is important for identifying specific types of cancer from EUS-FNA samples (18). Definitively diagnosing patients with suspected cancer from whom collecting biopsy or original cancer tissue is impractical due to gastrointestinal stenosis may be challenging. However, no previous reports on EUS-FNA of metastatic lymph nodes in such patients were identified in the present study. As the usefulness of EUS-FNA has been confirmed, a proactive use of EUS-FNA is recommended for cases in which clinicians' suspect metastatic lymphadenopathy.

EUS-FNA identified the origin of the metastases in $87.5 \%$ $(56 / 64)$ of the metastatic lymph nodes. The histopathological diagnosis differed from that which was expected based on the pre-procedural images in 9 patients; the cancer management strategy for these patients was subsequently changed. This result suggested that these patients may have received inappropriate treatment had they been diagnosed solely using the imaging results. Accordingly, the present study emphasized how important definitively diagnosing using EUS-FNA may be. However, the cancer was diagnosed without identifying the origin in certain patients and definitively diagnosing using EUS-FNA may be difficult in patients for whom the origin may not be identified by prior whole-body assessments. In such patients, further whole-body examinations will be necessary to identify the cancer origin, indicating the importance of detailed whole-body assessments in these patients.

To conclude, the present study found that EUS-FNA was not associated with complications in these patients, and that it was useful for diagnosing lymphadenopathy that could not be diagnosed solely based on images. In addition to EUS-FNA techniques, prior whole-body examinations including blood examination and imaging modalities are important for the diagnosis of lymphadenopathy.

\section{Competing interests}

The authors declare that they have no competing interests.

\section{References}

1. Mochizuki K, Gabata T, Kozaka K, Hattori Y,Zen Y, Kitagawa H, Kayahara M, Ohta T and Matsui O: MDCT findings of extra pancreatic nerve plexus invasion by pancreas head carcinoma: Correlation with en bloc pathological specimens and diagnostic accuracy. Eur Radiol 20: 1757-1767, 2010.

2. Raman SP, Chen Y and Fishman EK: Cross-sectional imaging and the role of positron emission tomography in pancreatic cancer evaluation. Semin Oncol 42: 40-58, 2015.

3. Bhutani MS, Hawes RH and Hoffman BJ: A comparison of the accuracy of echo features during endoscopic ultrasound (EUS) and EUS-guided fine-needle aspiration for diagnosis of malignant lymph node invasion. Gastrointest Endosc 45: 474-479, 1997.
4. Kanamori A, Hirooka Y, Itoh A, Hashimoto S, Kawashima H, Hara K, Uchida H, Goto J, Ohmiya N, Niwa Y and Goto H: Usefulness of contrast-enhanced endoscopic ultrasonography in the differentiation between malignant and benign lymphadenopathy. Am J Gastroenterol 101: 45-51, 2006.

5. Song HJ, Kim JO, Eun SH, Cho YD, Jung IS, Cheon YK, Moon JH, Lee MS, Shim CS, Kim BS and Jin SY: Endoscopic ultrasonograpic findings of benign mediastinal and abdominal lymphadenopathy confirmed by EUS-guided fine needle aspiration. Gut Liver 1: 68-73, 2007.

6. Eloubeidi MA, Wallace MB, Reed CE, Hadzijahic N, Lewin DN, Van Velse A, Leveen MB, Etemad B, Matsuda K, Patel RS, et al: The utility of EUS and EUS-guided fine needle aspiration in detecting celiac lymph node metastasis in patients with esophageal cancer: A single center experience. Gastrointest Endosc 54: 714-719, 2001.

7. Chen VK and Eloubeidi MA: Endoscopic ultrasound-guided fine needle aspiration is superior to lymph node echo features: A prospective evaluation of mediastinal and peri-intestinal lymphadenopathy. Am J Gastroenterol 99: 628-633, 2004.

8. Iwashita T, Yasuda I, Mukai T, Doi S, Nakashima M, Uemura S, Mabuchi M, Shimizu M, Hatano Y, Hara A and Moriwaki H: Macroscopic on-site quality evaluation of biopsy specimens to improve the diagnostic accuracy during EUS-guided FNA using a 19-gauge needle for solid lesions: A single-center prospective pilot study (MOSE study). Gastrointest Endosc 81: 177-185, 2015.

9. Swerdlow SH, Campo E, Pileri SA, Harris NL, Stein H, Siebert R, Advani R, Ghielmini M, Salles GA, Zelenetz AD and Jaffe ES: The 2016 revision of the World Health Organization classification of lymphoid neoplasms. Blood 127: 2375-2390, 2016.

10. Bhatia V and Varadarajulu S: Endoscopic ultrasonography-guided tissue acquisition: How to achieve excellence. Dig Endosc 29: 417-430, 2017.

11. Nakahara O, Yamao K, Bhatia V, Sawaki A, Mizuno N, Takagi T, Shimizu Y, Koshikawa T, Yatabe Y and Baba H: Usefulness of endoscopic ultrasound-guided fine needle aspiration (EUS-FNA) for undiagnosed intra-abdominal lymphadenopathy. J Gastroenterol 44: 562-567, 2009.

12. Srinivasan R, Bhutani MS, Thosani N, Săftoiu A, Rice DC, Ioncică AM, Eapen GA, Gupta P, Jaganmohan S, Artifon EL and Zwischenberger JB: Clinical impact of EUS-FNA of mediastinal lymph nodes in patients with known or suspected lung cancer or mediastinal lymph nodes of unknown etiology. J Gastrointestin Liver Dis 21: 145-152, 2012.

13. Nguyen TQ, Kalade A, Prasad S, Desmond P, Wright G, Hart D, Conron $M$ and Chen RY: Endoscopic ultrasound guided fine needle aspiration (EUS-FNA) of mediastinal lesions. ANZ J Surg 81: 75-78, 2011.

14. Micames CG, McCrory DC, Pavey DA, Jowell PS and Gress FG: Endoscopic ultrasound-guided fine-needle aspiration for non-small cell lung cancer staging: A systematic review and metaanalysis. Chest 131: 539-548, 2007.

15. Gleeson FC, Clain JE, Karnes RJ, Rajan E, Topazian MD, Wang KK and Levy MJ: Endoscopic ultrasound-guided tissue sampling facilitates the detection of local recurrence and extra pelvic metastasis in pelvic urologic malignancy. Diagn Ther Endosc 2012: 219521, 2012.

16. Yasuda I, Tsurumi H, Omar S, Iwashita T, Kojima Y, Yamada T, Sawada M, Takami T, Moriwaki H and Soehendra N: Endoscopic ultrasound guided fine-needle aspiration biopsy for lymphadenopathy of unknown origin. Endoscopy 38: 919-924, 2006.

17. Polkowski M, Larghi A, Weynand B, Boustière C, Giovannini M, Pujol B and Dumonceau JM; European Society of Gastrointestinal Endoscopy (ESGE): Learning, techniques, and complications of endoscopic ultrasound (EUS)-guided sampling in gastroenterology: European society of gastrointestinal endoscopy (ESGE) technical guideline. Endoscopy 44: 190-206, 2012.

18. Iglesias-Garcia J, Lariño-Noia J, Abdulkader I and DomínguezMuñoz JE: Rapid on-site evaluation of endoscopic-ultrasoundguided fine-needle aspiration diagnosis of pancreatic masses. World J Gastroenterol 20: 9451-9457, 2014.

This work is licensed under a Creative Commons Attribution-NonCommercial-NoDerivatives 4.0 International (CC BY-NC-ND 4.0) License. 